\begin{tabular}{c} 
International Journal Of Engineering \& Technology, 7 (4.37) (2018) 76-78 \\
International Journal Of Engineering \& Technology \\
SPC \\
Rebsite: Www.Sciencepubco.Com/Index.Php/IJET \\
Research PaperResearch paper, Short communication, Review, Technical paper \\
\hline
\end{tabular}

\title{
Prediction the Manning's Coefficient by HEC-RAS for Al-Meshkab River
}

\author{
Jumana Hadi Sahib* \\ Department of Civil engineering, University of Kufa, Kufa, Iraq \\ *Corresponding author E-mail: jumanah.alsabarawi@uokufa.edu.iq
}

\begin{abstract}
The Manning's coefficient represents the roughness characteristics of the channel, which directly affects open channel calculations. In this study, it been calculated which estimation of Manning's coefficient (n) by some of the collected data .The remaining data is utilized for check of the model testing with actual data, which is called verification. The model was adopted by a one-dimensional mathematical by using the HEC-RAS program. The region was studied at the upstream of the Al-Meshkab Barrage, where data were collected in 2010. The coefficient of Manning's roughness ( $\mathrm{n}$ ) is given well agreement between computed data and observed data at $\mathrm{n}$ equal to (0.031) for Al-Meshkab River.
\end{abstract}

Keywords: bed roughness, Manning's Coefficient, river, calibration, verification, HEC-RAS program Semicolon.

\section{Introduction}

In open channels flow, all hydraulic computations required the information about roughness properties of the channel. Also, it is mainly key to successfully predicting water flow in open channel networks. Al-Meshkab River extends for a distance of about $(6 \mathrm{~km})$ in a rural agricultural area which contain many villages, as shown in Fig. (1). It are located at both sides the river. The mainly river go over through alluvial zone with favorable conditions of climate. The detailed of hydrodynamics for the river are not available. Hardly determination coefficient of roughness (n) in natural channels. This main reason, setting the hydraulic river model. (Chow, 1959) was mentioned the factors affecting the roughness coefficient.

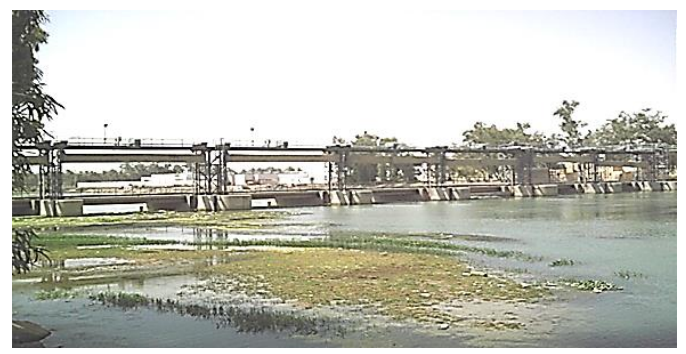

Fig. 1: Al-Meshkab regulator Project, taken in 2010

(Fenton, 2002); the value of (n) is (0.025) for natural irrigation channels. For earth channels; (Gupta, 2007) reported ranges with (0.022 to 0.033$)$. Past studies for natural Iraqi rivers flow pointed the Manning's value (n) that may differ between (0.025-0.04) [Jabaar, (1985)] [Quoted in: Shaker (1985) cited by Hameed, (2011)]. For the beginning, the numerical calculation is selected by HEC-RAS software.

\section{The Modeling in HEC-RAS Software}

The US Army Corps of Engineers were developed the Hydrologic Engineering Center River Analysis System (HEC-RAS) program (Stevenson et al, 2009). That program is used for long time to onedimensional simulations of flow in river (Kalaba, 2014). The program is a professional and simple for one-dimensional computations, the HEC-RAS considered as a good tool for the model hydraulic to setup hydrology calculations. Widely, it utilized for calculations of profile water surface in case of one-dimensional for unsteady and steady flow river. As well as, it components numerical calculations for one-dimensional sediment transport (HEC-RAS, 2010). Fig. (2) represent main windows to menu HEC-RAS model.

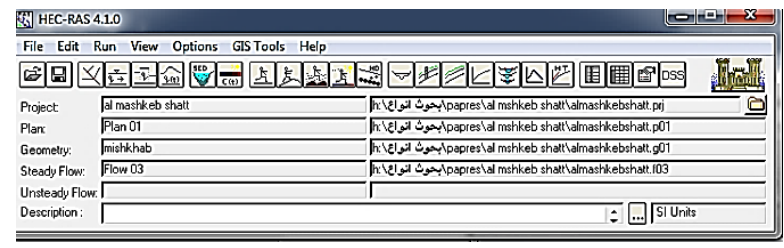

Fig.2: Main windows of HEC-RAS program

To make a mathematical model in the HEC-RAS program, the scheme reach of river is brought from google maps loaded in the editor of geometric data in HEC-RAS, Fig.(3). A path diagram must represented the shape of the river. The path must be started from the upstream to the downstream of flow. The river sections represented by elevation and station points, sub-reach lengths and main channel bank stations along the whole river system to represent the path reach ( 24 sections). The information required shown on editor for data cross-section as in Fig. (4). 


\section{Calibration and Verification Processes For the AL-Meshkab HEC-RAS}

In this study, the data of cross sections collected by (Addab, 2011). Which divided into two sets; the first one is used for calibration purpose; i.e. estimation of (n) and the rest for verification.

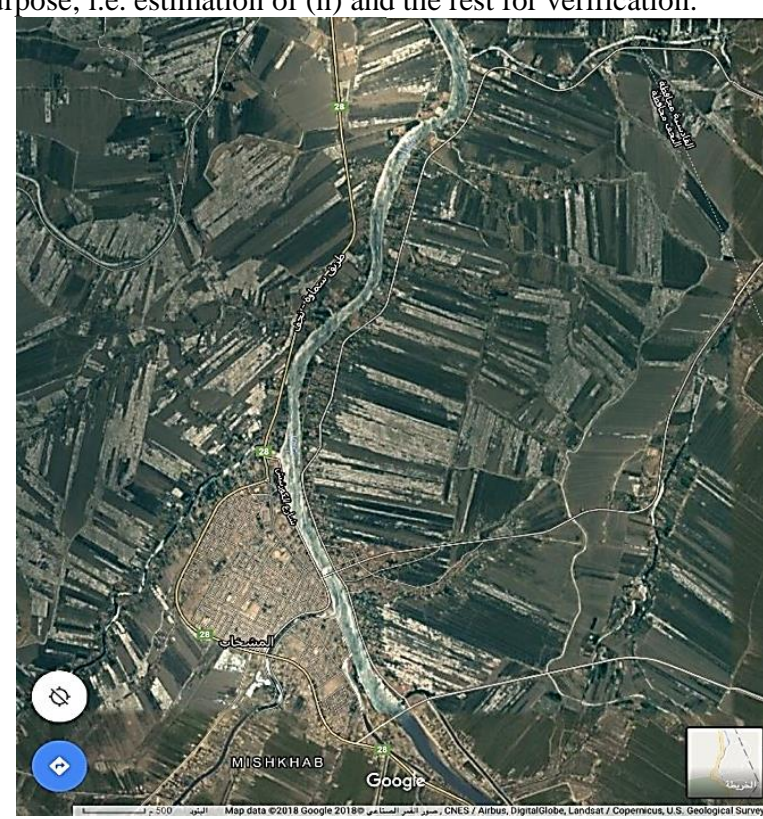

Fig. 3: topographic map of the Al-Meshkab system

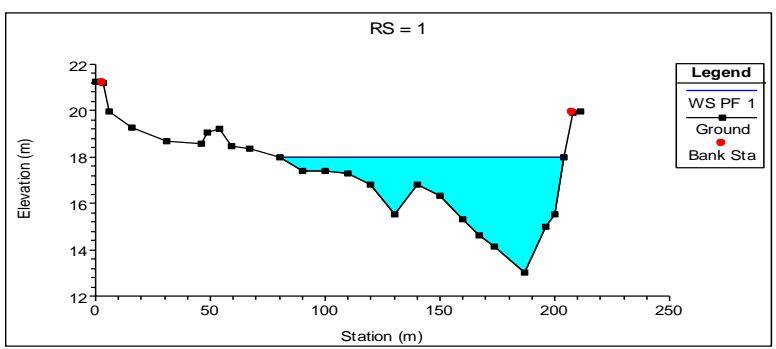

Fig. 4: cross section for Al- Meshkab Rive

The boundary condition for steady flow model consists of normal depth with slope $\left(0.78 \times 10^{-4}\right)$, Fig. (5). The observed discharge range from (66.1-95.6) is used as steady flow data. The observed stage profile as shown in Fig. (6) is used to compered with measured data.

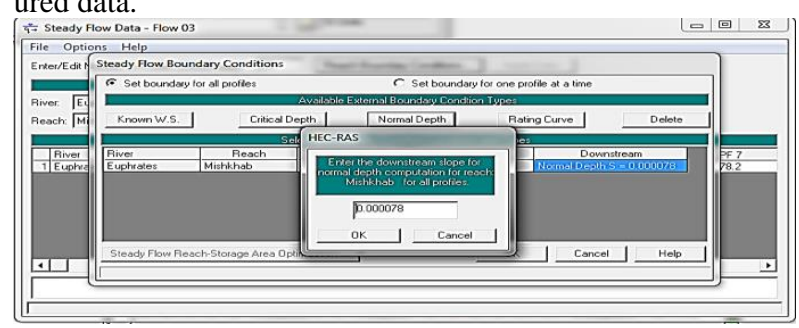

Fig 5: steady flow data

In this model of simulation, for Al-Meshkab River the values of Manning's roughness coefficient are assumed between from 0.021 to 0.043 . The model Results with these values of Manning coefficient a closer agreement obtained with $(n=0.031)$ value as shown in Figs (7) and (8).

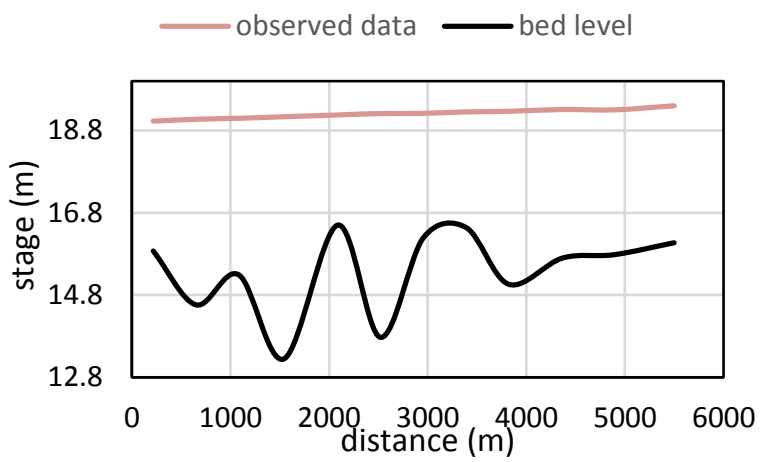

Fig 6: The observed stage

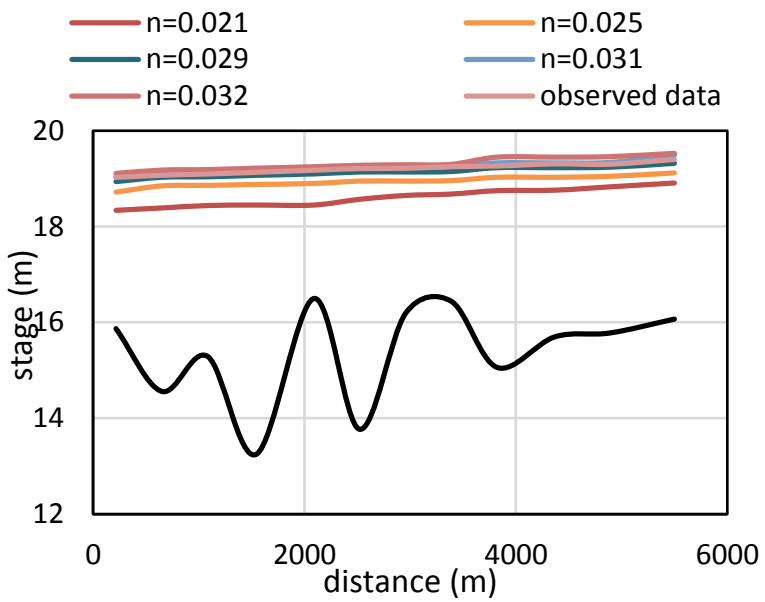

Fig. 7: Observed and computed stage by various values of (n) between $(0.021-0.032)$

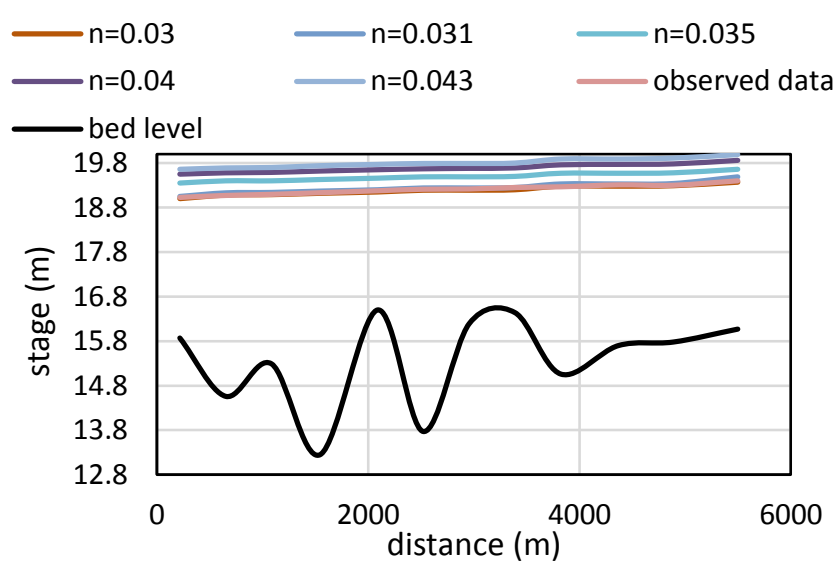

Fig. 8: Observed and computed stage by various values of (n) between (0.03-0.043)

\section{Statistical Test for the Result of Calibration}

Verify of the calibration process must be used a statistical test with the observed data. In this study is used the root-mean-square (R.M.S.) test. The table no. (1) shows the calibration results of the statistical test ; the values of (R.M.S.). These values are compared results between the computed and observed stage. 
Table 1: The R.M.S Test for the Calibration Results.

\begin{tabular}{|c|c|c|}
\hline $\begin{array}{c}\text { No. Of (N) Cali- } \\
\text { brated }\end{array}$ & Value Of (N) & R.M.S. \\
\hline 1 & 0.021 & 1.344427 \\
\hline 2 & 0.025 & 0.801457 \\
\hline 3 & 0.03 & 0.172754 \\
\hline 4 & 0.031 & 0.056404 \\
\hline 5 & -0.032 & 0.06403 \\
\hline 6 & 0.035 & 0.480443 \\
\hline 7 & 0.04 & 1.154053 \\
\hline 8 & 0.043 & 1.456156 \\
\hline
\end{tabular}

Verification process is a fundamental for any simulation model, which applied through anther cross section as shown in fig (9) using the value $(n=0.031)$ obtained from calibration process. The model of verification made by a comparison between the computed and observed data. The process of verification results display the Manning's value of (0.031) reasonably makes data nearer to the observed data as shown in Fig.(10). The result (R.M.S.) for stage is 0.093 . Analysis of results shows acceptable this model

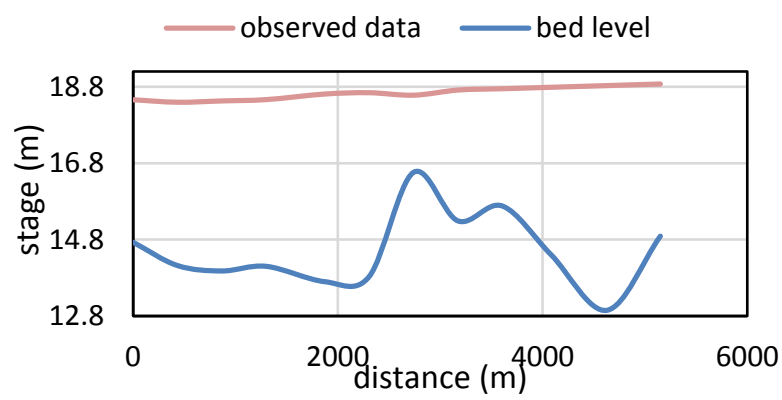

Fig. 9: observed stage for verification process

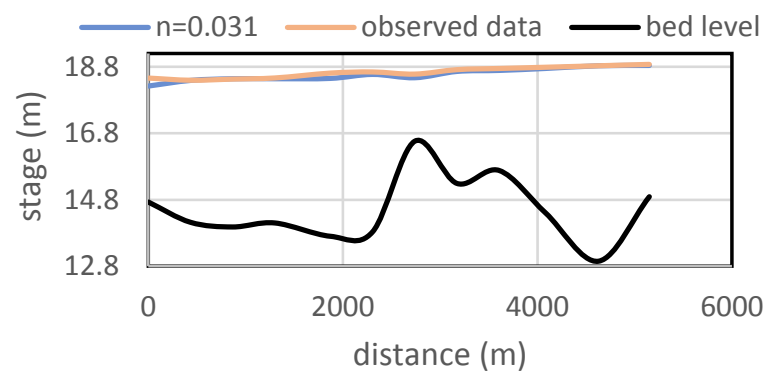

Fig. 10: Computed and observed stage $(n=0.031)$

\section{Conclusion}

Calibration procedure is used to predict Manning's coefficient (n) by HEC-RAS program for the upstream of Al-Meshkab Barrage reach. The suitable Manning's value is $(0.031)$, it record an acceptable agreement between observed and computed stage profile.

\section{References}

[1] Addab H. F 2011. Estimation of Sediment Quantity of Al-Meshkab Regulator Channel. M.Sc. thesis, College of Engineering, University of Kufa, Iraq.

[2] Chow, V.T. 1959. Open-channel hydraulics. McGraw-Hill, New York.

[3] Fenton, J. D. 2002. The application of Numerical Methods and Mathematics to Hydrography. Proc. 11th Australasian Hydrographic Conference, 3-6 July, Sydney.

[4] Fread, D.L. and Lewis, J.M. 1998. NWS FLDWAV Model. Hydrologic Research Laboratory. Office of Hydrology, National Weather Service (NWS), NOAA.

[5] Gupta, B.L. 2007. Water resources systems and management._2nd edition .ISBN:81-8014-106-3, Standard Publishers, Delhi. www. engineeringbooks.co.in

[6] HEC (Hydrologic Engineering Center). 2009. One- dimensiona unsteady flow through a full network of open channels. User's manual, U.S. Army Corps of Engineers, Davis, CA. (http://www.hec.usace.army. mil/software/hec-ras/hecrasdownload. html).

[7] Hameed L. K. 2011.Inverse Routing of Flood Wave for Shat ALHilla River. M.Sc. thesis, College of Engineering, University of Babylon, Iraq.

[8] Kalabaa,D. Ivana, I. and. Cikara,D, 2014.The inital analysis of the river IBAR Temperature downstream of the lake GAZIVODE. A Faculty of Mechanical Engineering, University of Pristina, Kosovska Mitrovica, Serbia.

[9] Stevenson, D. 2009.1-D HEC-RAS Model and Sensitivity Analysis for St. Clair River from 1971 - 2007. International Joint Commission International Upper Great Lakes Study 234 Laurier Ave. W, 22nd Floor Ottawa, ON, K1P 6K6. 